\title{
Animal models for human herpesvirus 6 infection
}

\author{
Joséphine M. Reynaud and Branka Horvat* \\ International Center for Infectiology Research, INSERM U1111, CNRS UMR5308, ENS Lyon, University of Lyon 1, Lyon, France
}

Edited by:

Akio Adachi, The University of

Tokushima Graduate School, Japan

\section{Reviewed by:}

Yasuko Mori, Kobe University, Japan Naoki Inoue, National Institute of

Infectious Diseases, Japan

\section{*Correspondence:}

Branka Horvat, International Center for Infectiology Research, INSERM U1111, CNRS UMR5308, ENS Lyon, University of Lyon 1, Tour CERVI,

21 Avenue Tony Garnier, 69365 Lyon, France

e-mail:branka.horvat@inserm.fr
Human herpesvirus (HHV)-6A and HHV-6B are two enveloped DNA viruses of $\beta$-herpesvirus family, infecting over $90 \%$ of the population and associated with several diseases, including exanthema subitum (for HHV-6B), multiple sclerosis and encephalitis, particularly in immunosuppressed patients. Animal models are highly important to better understand the pathogenesis of viral infections. Naturally developed neutralizing antibodies to HHV-6 or a related virus were found in different species of monkeys, suggesting their susceptibility to HHV-6 infection. Both HHV-6 DNA and infectious virus were detected in experimentally infected Cynomolgus and African green monkeys, although most animals remained clinically asymptomatic. Furthermore, HHV-6A infection was shown to accelerate the progression of AIDS (acquired immunodeficiency syndrome) in macaques and to lead to the development of neurological symptoms in the marmoset model. Humanized SCID (severe combined immunodeficiency) mice efficiently replicated HHV-6 and were also susceptible to coinfection with HHV-6 and HIV-1 (human immunodeficiency virus 1). As CD46 was identified as a receptor for HHV-6, transgenic mice expressing human CD46 may present a potentially interesting model for study certain aspects of HHV-6 infection and neuroinflammation.

Keywords: HHV-6, animal model, mouse, monkey, HIV, AIDS, neuroinflammation, CD46

\section{INTRODUCTION}

Human herpesvirus (HHV)-6 belongs to the $\beta$-Herpesviridae subfamily, together with its closest homolog HHV-7 and human cytomegalovirus (HCMV). The two variants of HHV-6, HHV$6 \mathrm{~A}$ and HHV-6B, have recently been recognized as two distinct viruses by the international committee on taxonomy of viruses, based mostly on their known genetic and epidemiological features (Braun et al., 1997). Primary infection with HHV-6B was identified as the etiological cause for roseola (exanthema subitum), a common febrile illness in infants (Yamanishi et al., 1988), whereas primary infection with HHV-6A has not yet been clearly associated to any specific disease. Like most herpesviruses, HHV-6A and $-6 \mathrm{~B}$ are able to establish asymptomatic long-term persistence in their hosts, and can reactivate under specific conditions. Although the mechanisms of reactivation are not yet completely understood, both viruses are known to reactivate in immunosuppressed patients, causing a variety of complications such as encephalitis, hepatitis, or graft rejection (Dockrell and Paya, 2001; Zerr, 2006). In addition, HHV-6A and $-6 \mathrm{~B}$ have been associated with several neurological diseases in the immunocompetent population. Indeed, numerous clinical studies have established a correlation between HHV-6A and -6B infection and the demyelinating, autoimmune disease-multiple sclerosis (reviewed in Reynaud and Horvat, 2013), and both viruses are thought to be involved in the development of certain cases of encephalitis, meningitis, and epilepsy (Theodore et al., 2008; Yao et al., 2010).

Human herpesvirus-6 has often been isolated from patients with acquired immunodeficiency syndrome (AIDS) and was suggested to play a role in the progression of this disease. Indeed, an active and wide-spread HHV-6 infection was observed in AIDS patients (Knox and Carrigan, 1994; Secchiero etal., 1995) and
AIDS was described to progress rapidly after primary HHV-6 infection in children with vertically inherited human immunodeficiency virus (HIV; Kositanont et al., 1999). Both HHV-6 and HIV have a preferential tropism toward $\mathrm{CD}^{+} \mathrm{T}$ cells and can establish simultaneous productive infection with synergistic cytopathic effects (Lusso et al., 1989). Moreover, HHV-6 has a wider range of susceptible cell types than HIV-1 and was shown to induce the expression of the HIV-1 receptor CD4 on immune cells that do not naturally express this molecule, rendering them, thus, susceptible to HIV-1 infection (Lusso et al., 1993, 1995). However, in the context of both AIDS and different other HHV-6-related pathologies, the consequences of coinfection and the potential mechanisms involved in the pathogenesis remain to be elucidated.

A few antiviral drugs have been shown to be efficient against HHV-6 infection in vitro (Manichanh et al., 2000; De Clercq et al., 2001; De Bolle et al., 2005b) and were successfully used for the treatment of patients suffering from encephalitis following viral reactivation (reviewed in De Bolle et al., 2005b). However, these treatments are often associated with strong adverse effects and fully controlled specific clinical studies demonstrating their in vivo efficiency are still missing. Animal models represent very useful tools for preclinical analyses of potential antiviral drugs and for the study of viral pathogenesis. Here, we review the different animal models developed for the study of HHV-6A and/or HHV-6B infection (Table 1) and discuss the data obtained. In particular, the use of animal models has brought new evidence of the capacity of HHV-6A to induce neuropathology and has allowed the study of the interactions between HHV- 6 and immunodeficiency viruses, showing a role of HHV-6A in AIDS progression and providing potential explanations for the impact of HHV-6A on the course of HIV infection. 


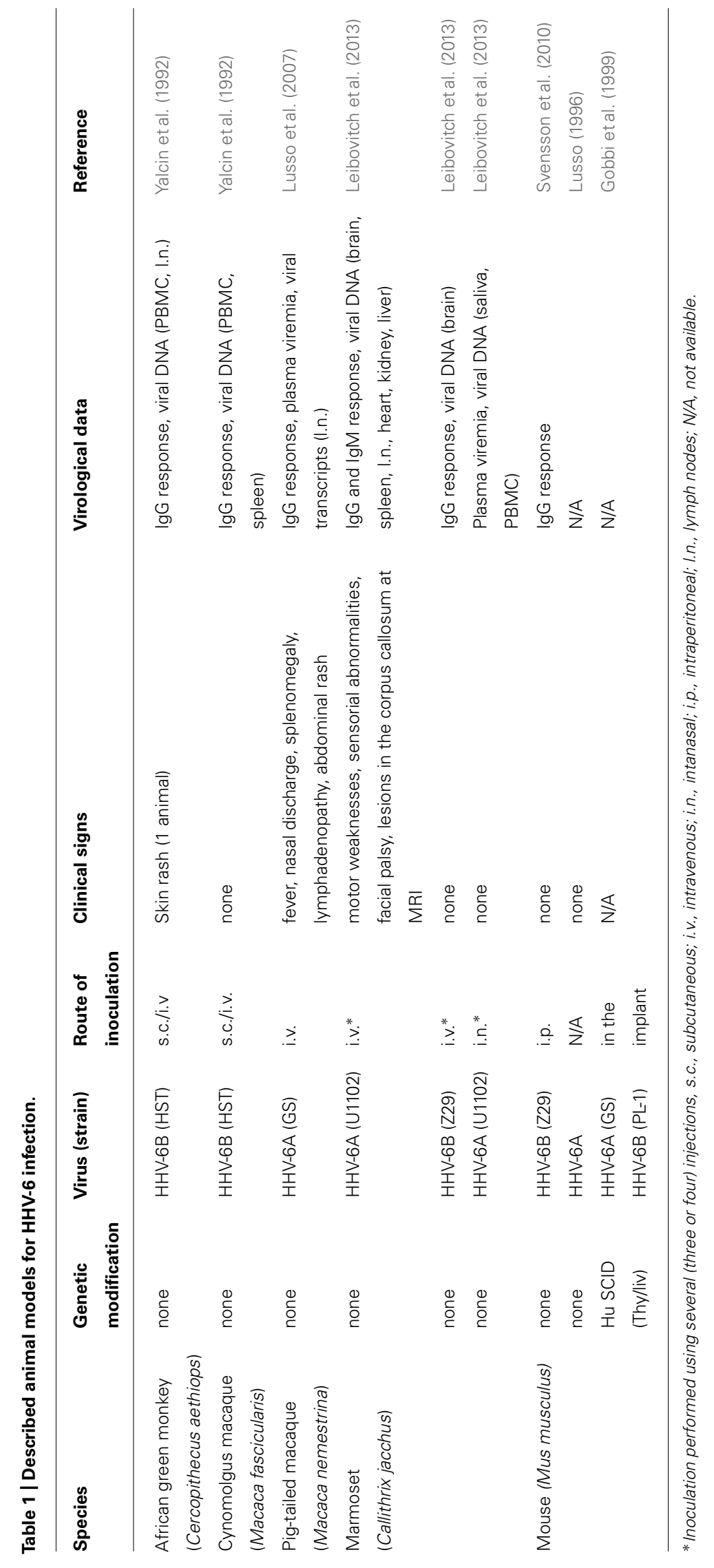




\section{SIMIAN MODELS}

\section{NATURAL INFECTION IN MONKEYS}

Shortly after the discovery of HHV-6, several groups have searched for evidence of natural infection by HHV-6 in monkeys. Initial studies first reported an absence of specific antibodies in several species of new- and old-world non-human primates (Salahuddin et al., 1986; Lusso et al., 1990). In contrast, another study carried out on 10 different species of monkeys revealed the presence of HHV-6-reactive antibodies, suggesting a previous infection either by HHV-6 or a closely related virus (Higashi et al., 1989). Among the tested species, eight were positive in immunofluorescence assay and seroneutralization. African green monkeys, squirrel monkeys, chimpanzees, and orangutan appeared to be the most frequently infected, with $75-100 \%$ of prevalence. Furthermore, several groups of monkeys of the same species but from different locations exhibited similar prevalence rates, thus suggesting that the susceptibility to HHV-6 infection may be speciesdependent.

More recently, a simian homolog of HHV-6 was isolated from blood samples from chimpanzees (Pan troglodytes; Lacoste et al., 2005). This new member of the $\beta$-herpesvirus group, called PanHV6, was found to be particularly close to the Z29 strain of HHV-6B. It was detected in several different subspecies of wild-caught chimpanzees from Cameroon and Gabon, but also in animals born in captivity in the Netherlands, indicating that this virus is present in different populations of chimpanzees. Several simian homologs of other human herpesviruses, including HCMV and Epstein-Barr virus (EBV; Davison et al., 2003; Ehlers et al., 2003) have been identified, which supports the theory that these viruses might have co-evolved with their host species. The natural susceptibility of some species of monkeys to infection with HHV-6 or a simian counterpart indicates that monkeys may represent an appropriate model for the study of HHV-6A and/or $-6 \mathrm{~B}$ pathogenesis.

\section{EXPERIMENTAL INFECTION IN SIMIAN MODELS Infection of simian cells}

Analyses performed on in vitro-infected peripheral blood mononuclear cells (PBMCs) from several species of monkeys, indicated that cells from chimpanzees and macaques (Macaca nemestrina and M. mulatta) are the most susceptible to infection by HHV-6 (Lusso etal., 1990, 1994). The infection of PBMCs led to the production of viral proteins and viral particles, observed by immunofluorescence and electron microscopy. Infection seemed highly variable among the species of monkeys tested and depended on the virus used (A or B). PBMCs from rhesus macaques ( $M$. mulatta) were found to be susceptible to HHV$6 \mathrm{~B}$ infection only, while PBMCs from pig-tailed macaques $(M$. nemestrina) were infected with similar efficiency by both HHV-6A and $-6 \mathrm{~B}$.

\section{African green monkeys and cynomolgus macaques}

The first experiments of in vivo HHV-6 infection in monkeys were conducted using African green monkeys (Cercopithecus aethiops) and cynomolgus macaques (M. fascicularis; Yalcin et al., 1992). Four animals from each species were inoculated with the HST strain of HHV-6B. Monkeys received a single subcutaneous (s.c.) or intravenous (i.v.) injection of $10^{5}$ half maximal tissue culture infective doses $\left(\mathrm{TCID}_{50}\right)$, and were monitored for 33 days. Following virus inoculation, a specific antibody response was detected, as well as the presence of viral DNA in the PBMCs and in the spleen and lymph nodes of some animals. However, the infection remained asymptomatic in all animals, except for one African green monkey, which developed a skin rash on the trunk (Table 1).

\section{Pig-tailed macaques}

Infection with HHV-6A was later described in pig-tailed macaques (M. nemestrina; Lusso et al., 2007). After i.v. inoculation with HHV-6A (GS strain), clinical symptoms of mild to moderate intensity were observed, including fever, nasal discharge, splenomegaly, generalized lymphadenopathy and abdominal rash (in one animal). Moreover, in this model, systemic infection was confirmed by the detection of viral DNA in the plasma, the development of an antibody response, and the presence of viral transcripts in the lymph nodes.

Furthermore, this model has been used to analyze coinfection with HHV-6A and simian immunodeficiency virus (SIV), a simian counterpart of HIV-1 typically used for experimental infection in macaques (Lusso et al., 2007). This approach provided the first in vivo data showing that HHV-6A infection can accelerate AIDS progression. Indeed, although $\mathrm{HHV}-6 \mathrm{~A}$ infection did not seem to have any effect on SIV spreading, dually infected animals exhibited faster depletion in $\mathrm{CD}^{+}{ }^{+} \mathrm{T}$ cells than the singly SIV-infected ones. Interestingly, $\mathrm{HHV}-6 \mathrm{~A}$ infection also resulted in a faster decrease in $\mathrm{CD}^{+}{ }^{+} \mathrm{T}$ cell count, which could be due to HHV-6A-induced de novo expression of CD4 in these cells.

A potential mechanism explaining the enhancement of AIDS by HHV-6A was suggested following the analysis of the virus isolated from monkeys receiving either single SIV infection or HHV-6A/SIV coinfection (Biancotto et al., 2009). In vitro replication of viral isolates obtained from singly infected monkeys was inhibited by coinfection with HHV-6A, and treatment with the chemokine CCL5 (regulated upon activation normal $\mathrm{T}$ cell expressed and secreted, RANTES) had similar effects. In contrast, all isolates from dually infected monkeys appeared to be resistant to both CCL5 treatment and HHV-6A infection, suggesting that in vivo coinfection with $\mathrm{HHV}-6 \mathrm{~A}$ probably directs SIV evolution toward CCL5 resistance. Thus HHV-6A infection could create a high-CCL5 environment in vivo, in which CCL5-resistance would be advantageous for efficient SIV replication.

\section{The marmoset model: evidence for HHV-6A-induced neurological disease}

A recent study described a new model of infection by both HHV6A and -6B using common marmosets (Callithrix jacchus), which represents so far the only model of HHV-6A infection associated with the more important clinical signs (Leibovitch et al., 2013). Indeed, HHV-6A-infected monkeys that received several monthly i.v. injections developed clear neurological symptoms, including motor weakness and sensory abnormalities. Moreover, magnetic resonance imaging (MRI) analyses revealed the presence of hyperintense lesions in the brain of one animal. This study provided the first in vivo evidence that HHV-6A infection is able to trigger 
neurological disease. In humans, both HHV-6A and -6B DNA was shown to be present in the brain of healthy people, indicating that both species have similar neuroinvasive properties. In marmosets, viral DNA was also occasionally detected in the brain of HHV6A- and -6B-infected animals, which confirmed the capacity of both viruses to reach the brain. However, while HHV-6A infection led to evident neurological symptoms, infection with HHV-6B remained asymptomatic, thus showing an important difference between HHV-6A and $-6 \mathrm{~B}$ in their ability to infect marmosets (Table 1).

Interestingly, an additional group of marmosets was infected with HHV-6A through the intranasal (i.n.) route of inoculation, which resulted in radically different clinical outcomes. Based on histological data, the i.n. pathway was proposed as a possible route of transmission and access to the brain for HHV-6A in humans (Harberts et al., 2011). Contrary to i.v.-injected marmosets, i.n.injected animals did not exhibit any sign of disease. Moreover, i.n.-inoculated animals rarely developed antibody responses and maintained plasma viremia, whereas i.v. injection led to the development of HHV-6-specific antibody responses and clearance of viral DNA in the plasma. These results suggested that the neurological symptoms observed with i.v. injection might be due to the immune response developed against the virus rather than to the direct consequences of viral infection and spreading. This model therefore emphasizes the importance of the route of inoculation in viral pathogenesis, and provides a clear in vivo demonstration that HHV-6A can cause a neurological disease with MS-like symptoms. The marmoset model thus appears as an appropriate model for the analysis of HHV-6A-induced neurological disease, and confirms the correlation between HHV-6 infection and the development of multiple sclerosis.

\section{MURINE MODELS}

The possibility of using a murine model to study HHV-6 infection has been attractive to the scientific community since the discovery of HHV-6. However, mice were initially described to be resistant to HHV-6 infection (Lusso, 1996). Nevertheless, a few studies have described the use of in vitro or in vivo murine models for the study of HHV-6.

\section{SUSCEPTIBILITY OF MURINE CELLS TO HHV-6 INFECTION}

The susceptibility to infection by HHV-6A and HHV-6B of several human and non-human cell lines was analyzed in a few studies. Both viruses failed to replicate in the murine mammary carcinoma cell line FM3A and viral transcripts were not detected in these cells, suggesting that murine cells are not permissive to infection by HHV-6 (De Bolle et al., 2005a). However, another study showed that infection by HHV-6A and HHV-6B enables the transcription of viral genes in murine primary oligodendrocyte precursors, although viral replication was not observed (Mock et al., 2006), suggesting that the susceptibility to HHV-6 infection may, to some extent, depend on the cell type analyzed. In addition, both HHV-6A and HHV-6B could induce cell cycle arrest in these cells, similarly, to what was previously observed in human oligodendrocyte precursor cells (Dietrich et al., 2004), indicating that some murine cell types could be used as a model to study certain aspects of HHV-6 infection in vitro.

\section{IN VIVO MURINE MODELS FOR THE STUDY OF HHV-6 INFECTION}

It has been reported that natural resistance of mice to herpesvirus infection, particularly against herpes simplex virus (HSV) is genetically determined and linked to major histocompatibility complex (MHC) genes (Lopez, 1975). Balb/c mice were among the most susceptible lines and were recently used to analyze the link between HHV-6B infection and allergy (Svensson et al., 2010). Although systemic infection was not observed, inoculation of UV-inactivated virus resulted in the development of specific IgG responses and had protective effects against the development of allergy by limiting the inflammation in lungs, thus suggesting the immunosuppressive effects of HHV-6B in vivo.

To overcome natural resistance of mice to HHV-6 infection another approach using immunodeficient mice was developed, aiming to provide an in vivo environment for the study of human tissue rather than to analyze the infection in mice. For this purpose, severe combined immunodeficiency (SCID) mice were used. These mice carry a mutation which provokes profound $\mathrm{T}$ and $\mathrm{B}$ lymphopenia, allowing the engraftment of heterologous tissues (McCune, 1996). SCID mice were humanized by coimplanting human fetal thymus and liver under the murine kidney capsule, permitting the growth of a unique thy/liv organ which histologically resembles human thymus. Mice carrying thy/liv organ support human lymphopoiesis, thus allowing the study of human lymphoid cells in an in vivo context, and were used for the study of other human viruses, especially for human immunodeficiency virus (HIV; Van Duyne et al., 2009). Inoculation with HHV-6A or $-6 \mathrm{~B}$ was performed by direct injection in the implant and led to productive infection of human thymic cells, associated with a strong thymic depletion (Gobbi et al., 1999). That study demonstrated that HHV-6 infection is able to induce immunosuppression in an in vivo context, which may explain how HHV-6 could enhance the progression of immunodeficiency in AIDS patients. In this model, HHV-6 seemed to exhibit a particular tropism toward intra-thymic T progenitor cells (ITTPs), a rapidly dividing subset of thymic cells which gives rise to other thymocytes at later stages of maturation. This study suggested that lytic infection of ITTPs may play an important role in the HHV-6-induced thymic depletion.

Coinfection with HHV-6A or-6B and HIV-1 was later performed using the same model (Gobbi et al., 2000). Both viruses were found to be able to simultaneously infect the engrafted human tissue, yet infection with either virus did not seem to have any impact on the replication or virulence of the other.

\section{TOWARD NOVEL TRANSGENIC MURINE MODELS}

Other models of humanized mice are currently under investigation. A model of $\mathrm{rag} 2^{-/-} \gamma \mathrm{c}^{-/-}$mice, deficient for $\mathrm{T}$ and $\mathrm{B}$ lymphocytes and NK cells and engrafted with human hematopoietic stem cells (Chicha etal., 2005) is being developed for the analysis of HHV-6 (Tanner et al., 8th International Conference on HHV-6\&7, April 2013). The use of this model has allowed numerous advances in the field of retrovirology (Van Duyne et al., 2009) and will certainly help in the understanding of HHV-6 immunopathogenesis.

Human herpesvirus- 6 was shown to use the human protein CD46 as a cellular receptor for viral entry (Santoro et al., 
1999). This transmembrane protein is involved in the protection of host cells against complement lysis (Liszewski et al., 1991), through binding to $\mathrm{C} 3 \mathrm{~b}$ and $\mathrm{C} 4 \mathrm{~b}$ components of the complement (Figure 1), and was identified as the receptor for a variety of pathogens, including measles virus (vaccine strains), several serotypes of adenovirus and some pathogenic bacteria (Riley-Vargas et al., 2004). Moreover, it was recently found to bind the immunoregulatory molecule Jagged 1, a member of the Notch system (Le Friec etal., 2012; Figure 1). CD46 is ubiquitously expressed in humans and is mostly conserved in other primates (Seya etal., 1998). As viral tropism is determined by the pattern of expression of virus-specific cellular receptors, these molecules are key players in viral infection. Contrary to most primate CD46 proteins, murine CD46 has a lower percentage of identity with the human protein and its expression is restricted to the testis, which may account for the resistance of mice to infection. Therefore the generation of transgenic mice expressing human CD46 with a ubiquitous distribution, as in humans, could provide new perspectives for the development of animal models for HHV-6 infection. We have produced several lines of CD46 transgenic mice (Horvat et al., 1996; Marie et al., 2002) and used them to analyze the pathogenesis of HHV-6 infection. HHV-6A seemed to establish long-term persistence in the brain of these mice, and to induce leukocyte infiltration (Reynaud etal., 8th International Conference on HHV-6\&7, April 2013). Thus, CD46 transgenic mice may represent a potential new small animal model for the study of HHV-6A-induced neuroinflammation. Some studies have suggested that CD46 may not be the only receptor for HHV-6B entry (Mori et al., 2002, 2004), opening thus, perspectives for the development of additional transgenic models for this virus. The availability of many experimental tools for murine models should facilitate further studies of virus-host interaction and HHV-6 pathogenesis.

\section{CONCLUSION}

The development of relevant animal models is critical for a better understanding of viral pathogenesis, generating new diagnostic tools and assessing antiviral therapeutics and vaccines. Although animal models usually do not mimic all the aspects of the human

\section{DOMAINS}

\section{Ligand binding sites}

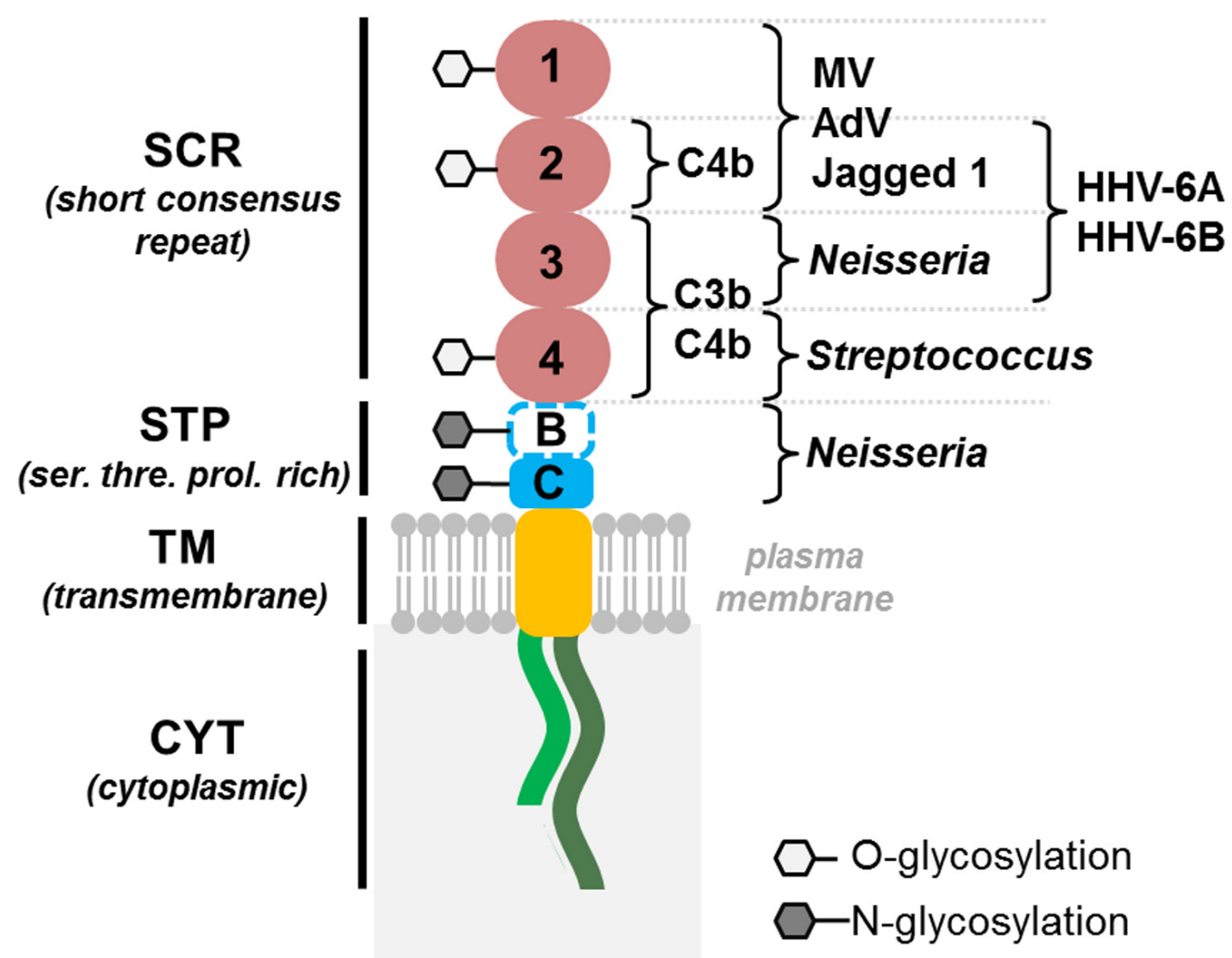

FIGURE 1 | Schematic representation of human HHV-6 receptor CD46, expressed in transgenic mice. CD46 consists of an extracellular part, with indicated binding site for different known CD46 ligands, transmembrane domain and one of two cytoplasmic tails: short, Cyt-1 or long, Cyt-2. MV, Measles Virus; AdV, Adenovirus. 
disease, they do reproduce at least some of them and could thus help in a better understanding of certain aspects of viral pathogenesis. The number of animal models to study HHV-6 infection is still rather limited and mainly includes non-human primates. Utilization of pig-tailed macaques provided evidence for the HHV-6-induced acceleration of AIDS and recently HHV-6A infection in marmosets has strongly suggested a link with neurological diseases. The latent nature of HHV-6 infection makes most in vivo studies often difficult to carry out. Recent advances

\section{REFERENCES}

Biancotto, A., Grivel, J.-C., Lisco, A., Vanpouille, C., Markham, P. D., Gallo, R. C., et al. (2009). Evolution of SIV toward RANTES resistance in macaques rapidly progressing to AIDS upon coinfection with HHV-6A. Retrovirology 6, 61. doi: 10.1186/1742-4690-6-61

Braun, D. K., Dominguez, G., and Pellett, P. E. (1997). Human herpesvirus 6. Clin. Microbiol. Rev. 10, 521-567. doi: 10.1086/322691

Chicha, L., Tussiwand, R., Traggiai, E., Mazzucchelli, L., Bronz, L., Piffaretti, J.-C., et al. (2005). Human adaptive immune system Rag2-/-gamma(c)-/- mice. Ann. N. Y. Acad. Sci. 1044, 236-243. doi: 10.1196/annals.1349.029

Davison, A. J., Dolan, A., Akter, P., Addison, C., Dargan, D. J., Alcendor, D. J., et al. (2003). The human cytomegalovirus genome revisited: comparison with the chimpanzee cytomegalovirus genome. J. Gen. Virol. 84, 17-28. doi: 10.1099/ vir.0.18606-0

De Bolle, L., Van Loon, J., De Clercq, E., and Naesens, L. (2005a). Quantitative analysis of human herpesvirus 6 cell tropism. J. Med. Virol. 75, 76-85. doi: 10.1002/jmv.20240

De Bolle, L., Naesens, L., and De Clercq, E. (2005b). Update on human herpesvirus 6 biology, clinical features, and therapy. Clin. Microbiol. Rev. 18, 217-245. doi: 10.1128/CMR.18.1.217-245.2005

De Clercq, E., Naesens, L., De Bolle, L., Schols, D., Zhang, Y., and Neyts, J. (2001). Antiviral agents active against human herpesviruses HHV-6, HHV7 and HHV-8. Rev. Med. Virol. 11, 381-395. doi: 10.1002/rmv.336

Dietrich, J., Blumberg, B. M., Roshal, M., Baker, J. V., Hurley, S. D., Mayer-Pröschel, M., et al. (2004). Infection with an endemic human herpesvirus disrupts critical glial precursor cell properties. J. Neurosci. 24, 4875-4883. doi: 10.1523/ JNEUROSCI.5584-03.2004

Dockrell, D. H., and Paya, C. V. (2001). Human herpesvirus-6 and 7 in transplantation. Rev. Med. Virol. 11, 23-36. doi: 10.1002/rmv.299
Ehlers, B., Ochs, A., Leendertz, F., Goltz, M., Boesch, C., and MätzRensing, K. (2003). Novel simian homologues of Epstein-Barr virus. J. Virol. 77, 10695-10699. doi: 10.1128/JVI.77.19.10695-10699.2003 Gobbi, A., Stoddart, C. A., Locatelli, G. Santoro, F., Bare, C., Linquist-Stepps, V., et al. (2000). Coinfection of SCIDhu Thy/Liv mice with human herpesvirus 6 and human immunodeficiency virus type 1. J. Virol. 74, 87268731. doi: 10.1128/JVI.74.18.87268731.2000

Gobbi, A., Stoddart, C. A., Malnati, M. S., Locatelli, G., Santoro, F., Abbey, N. W., et al. (1999). Human herpesvirus 6 (HHV-6) causes severe thymocyte depletion in SCID-hu Thy/Liv mice. J. Exp. Med. 189, 1953-1960. doi: 10.1084/jem.189.12.1953

Harberts, E., Yao, K., Wohler, J. E., Maric, D., Ohayon, J., Henkin, R., etal. (2011). Human herpesvirus- 6 entry into the central nervous system through the olfactory pathway. Proc. Natl. Acad. Sci. U.S.A. 108, 13734-13739. doi: 10.1073/pnas.1105143108

Higashi, K., Asada, H., Kurata, T., Ishikawa, K., Hayami, M., Spriatna, Y., et al. (1989). Presence of antibody to human herpesvirus 6 in monkeys. J. Gen. Virol. 70(Pt 12), 3171-3176. doi: 10.1099/0022-1317-70-12-3171

Horvat, B., Rivailler, P., VariorKrishnan, G., Cardoso, A., Gerlier, D., and Rabourdin-Combe, C. (1996). Transgenic mice expressing human measles virus (MV) receptor CD46 provide cells exhibiting different permissivities to MV infections. J. Virol. 70, 6673-6681.

Knox, K. K., and Carrigan, D. R. (1994). Disseminated active HHV-6 infections in patients with AIDS. Lancet 343, 577-578. doi: 10.1016/S01406736(94)91524-5

Kositanont, U., Wasi, C., Wanprapar, N., Bowonkiratikachorn, P., Chokephaibulkit, K., Chearskul, S., et al. (1999). Primary infection of human herpesvirus 6 in children with vertical infection of human immunodeficiency virus type 1 . J. Infect. Dis. 180, 50-55. doi: 10.1086/ 314826

in the development of murine models for HHV-6 infection, with numerous and powerful tools available, should be of critical help for in-depth immunobiological and genetic studies of HHV-6 infection.

\section{ACKNOWLEDGMENTS}

This work was supported by INSERM and ARSEP and Joséphine M. Reynaud was supported by a doctoral fellowship from the French ministry of research.

Lacoste, V., Verschoor, E. J., Nerrienet, E., and Gessain, A. (2005). A novel homologue of Human herpesvirus 6 in chimpanzees. J. Gen. Virol. 86, 2135-2140. doi: 10.1099/vir.0. 81034-0

Le Friec, G., Sheppard, D., Whiteman, P., Karsten, C. M., Shamoun, S. A.-T., Laing, A., et al. (2012). The CD46-Jagged1 interaction is critical for human TH1 immunity. Nat. Immunol. 13, 1213-1221. doi: 10.1038/ni.2454

Leibovitch, E., Wohler, J. E., Cummings Macri, S. M., Motanic, K., Harberts, E., Gaitán, M. I., et al. (2013). Novel marmoset (Callithrix jacchus) model of human Herpesvirus 6A and $6 \mathrm{~B}$ infections: immunologic, virologic and radiologic characterization. PLoS Pathog. 9:e1003138. doi: 10.1371/journal.ppat.1003138

Liszewski, M. K., Post, T. W., and Atkinson, J. P. (1991). Membrane cofactor protein (MCP or CD46): newest member of the regulators of complement activation gene cluster. Annu. Rev. Immunol. 9, 431-455. doi: 10.1146/annurev.iy.09.040191. 002243

Lopez, C. (1975). Genetics of natural resistance to herpesvirus infections in mice. Nature 258, 152-153. doi: $10.1038 / 258152 \mathrm{a} 0$

Lusso, P. (1996). Human herpesvirus 6 (HHV-6). Antiviral Res. 31, 1-21. doi: 10.1016/0166-3542(96)00949-7

Lusso, P., Crowley, R. W., Malnati, M. S., Di Serio, C., Ponzoni, M. Biancotto, A., et al. (2007). Human herpesvirus 6A accelerates AIDS progression in macaques. Proc. Natl. Acad. Sci. U.S.A. 104, 5067-5072. doi: 10.1073/pnas.0700929104

Lusso, P., Ensoli, B., Markham, P. D., Ablashi, D. V., Salahuddin, S. Z., Tschachler, E., et al. (1989). Productive dual infection of human CD4+ T lymphocytes by HIV-1 and HHV-6. Nature 337, 370-373. doi: 10.1038/337370a0

Lusso, P., Garzino-Demo, A., Crowley, R. W., and Malnati, M. S. (1995). Infection of gamma/delta T lymphocytes by human herpesvirus 6: transcriptional induction of CD4 and susceptibility to HIV infection.
J. Exp. Med. 181, 1303-1310. doi: 10.1084/jem.181.4.1303

Lusso, P., Malnati, M. S., GarzinoDemo, A., Crowley, R. W., Long, E. O., and Gallo, R. C. (1993). Infection of natural killer cells by human herpesvirus 6. Nature 362, 458-462. doi: 10.1038/362458a0

Lusso, P., Markham, P. D., DeRocco, S. E., and Gallo, R. C. (1990). In vitro susceptibility of T lymphocytes from chimpanzees (Pan troglodytes) to human herpesvirus 6 (HHV-6): a potential animal model to study the interaction between HHV-6 and human immunodeficiency virus type 1 in vivo. J. Virol. 64, 2751-2758.

Lusso, P., Secchiero, P., and Crowley, R. W. (1994). In vitro susceptibility of Macaca nemestrina to human herpesvirus 6: a potential animal model of coinfection with primate immunodeficiency viruses. AIDS Res. Hum. Retroviruses 10, 181-187. doi: 10.1089/aid.1994.10.181

Manichanh, C., Grenot, P., GautheretDejean, A., Debré, P., Huraux, J. M., and Agut, H. (2000). Susceptibility of human herpesvirus 6 to antiviral compounds by flow cytometry analysis. Cytometry 40, 135-140. doi: 10.1002/(SICI) 1097 0320(20000601)40:2

Marie, J. C., Astier, A. L., Rivailler, P., Rabourdin-Combe, C., Wild, T. F., and Horvat, B. (2002). Linking innate and acquired immunity: divergent role of CD46 cytoplasmic domains in T cell induced inflammation. Nat. Immunol. 3, 659-666. doi: 10.1038/ni810

McCune, J. M. (1996). Development and applications of the SCID-hu mouse model. Semin. Immunol. 8, 187-196. doi: 10.1006/ smim.1996.0024

Mock, D. J., Strathmann, F., Blumberg, B. M., and Mayer-Proschel, M. (2006). Infection of murine oligodendroglial precursor cells with Human Herpesvirus 6 (HHV-6) establishment of a murine in vitro model. J. Clin. Virol. .37(Suppl. 1), S17-S23. doi: 10.1016/S13866532(06)70006-3

Mori, Y., Akkapaiboon, P., Yonemoto, S., Koike, M., Takemoto, M., 
Sadaoka, T., et al. (2004). Discovery of a second form of tripartite complex containing gH-gL of human herpesvirus 6 and observations on CD46. J. Virol. 78, 4609-4616. doi: 10.1128/JVI.78.9.4609-4616.2004

Mori, Y., Seya, T., Huang, H. L., Akkapaiboon, P., Dhepakson, P., and Yamanishi, K. (2002). Human herpesvirus 6 variant A but not variant $B$ induces fusion from without in a variety of human cells through a human herpesvirus 6 entry receptor, CD46. J. Virol. 76, 67506761. doi: 10.1128/JVI.76.13.67506761.2002

Reynaud, J. M., and Horvat, B. (2013). Human herpesvirus 6 and neuroinflammation. ISRN Virol. 2013, 11.

Riley-Vargas, R. C., Gill, D. B., Kemper, C., Liszewski, M. K., and Atkinson, J. P. (2004). CD46: expanding beyond complement regulation. Trends Immunol. 25, 496-503. doi: 10.1016/j.it.2004.07.004

Salahuddin, S. Z., Ablashi, D. V., Markham, P. D., Josephs, S. F. Sturzenegger, S., Kaplan, M., et al. (1986). Isolation of a new virus, HBLV, in patients with lymphoproliferative disorders. Science 234, 596601. doi: $10.1126 /$ science. 2876520
Santoro, F., Kennedy, P. E., Locatelli, G., Malnati, M. S., Berger, E. A., and Lusso, P. (1999). CD46 is a cellular receptor for human herpesvirus 6 . Cell 99, 817-827. doi: 10.1016/S00928674(00)81678-5

Secchiero, P., Carrigan, D. R., Asano, Y., Benedetti, L., Crowley, R. W. Komaroff, A. L., et al. (1995). Detection of human herpesvirus 6 in plasma of children with primary infection and immunosuppressed patients by polymerase chain reaction. J. Infect. Dis. 171, 273-280. doi: 10.1093/infdis/171.2.273

Seya, T., Nomura, M., Murakami, Y., Begum, N. A., Matsumoto, M. and Nagasawa, S. (1998). CD46 (membrane cofactor protein of complement, measles virus receptor): structural and functional divergence among species (review). Int. J. Mol. Med. 1, 809-816.

Svensson, A., Almqvist, N., Chandy, A. G., Nordström, I., and Eriksson, K. (2010). Exposure to human herpes virus type 6 protects against asthma in mice. J. Allergy Ther. 1, 101.

Theodore, W. H., Epstein, L., Gail lard, W. D., Shinnar, S., Wainwright, M. S., and Jacobson, S. (2008). Human herpes virus 6B: a possible role in epilepsy? Epilepsia 49, 1828-1837. doi: 10.1111/j.15281167.2008.01699.x

Van Duyne, R., Pedati, C., Guendel, I., Carpio, L., Kehn-Hall, K., Saifuddin, M., et al. (2009). The utilization of humanized mouse models for the study of human retroviral infections. Retrovirology 6, 76. doi: 10.1186/1742-4690-6-76

Yalcin, S., Mukai, T., Kondo, K., Ami, Y., Okawa, T., Kojima, A., et al. (1992). Experimental infection of cynomolgus and African green monkeys with human herpesvirus 6. J. Gen. Virol. 73(Pt 7), 1673-1677. doi: 10.1099/0022-1317-73-7-1673

Yamanishi, K., Okuno, T., Shiraki, K., Takahashi, M., Kondo, T., Asano, Y., et al. (1988). Identification of human herpesvirus-6 as a causal agent for exanthem subitum. Lancet 1, 1065-1067. doi: 10.1016/S01406736(88)91893-4

Yao, K., Crawford, J. R., Komaroff, A. L., Ablashi, D. V., and Jacobson, S. (2010). Review part 2: human herpesvirus- 6 in central nervous system diseases. J. Med. Virol. 82, 1669 1678. doi: 10.1002/jmv.21861

Zerr, D. M. (2006). Human herpesvirus 6 and central nervous system disease in hematopoietic cell transplantation. J. Clin. Virol. 37(Suppl. 1), S52S56. doi: 10.1016/S1386-6532(06) 70012-9

Conflict of Interest Statement: The authors declare that the research was conducted in the absence of any commercial or financial relationships that could be construed as a potential conflict of interest.

Received: 30 April 2013; accepted: 11 June 2013; published online: 04 July 2013. Citation: Reynaud JM and Horvat B (2013) Animal models for human herpesvirus 6 infection. Front. Microbiol. 4:174. doi: 10.3389/fmicb.2013.00174

This article was submitted to Frontiers in Virology, a specialty of Frontiers in Microbiology.

Copyright (c) 2013 Reynaud and Horvat. This is an open-access article distributed under the terms of the Creative Commons Attribution License, which permits use, distribution and reproduction in other forums, provided the original authors and source are credited and subject to any copyright notices concerning any third-party graphics etc. 